\title{
Número mais provável (NMP) de coliformes fecais (E.coli) na avaliação do tempo de espera entre o descarregamento e o tratamento térmico de mexilhões comercializados no município de Niterói - Estado do Rio de Janeiro - Brasil
}

\section{Most Probable Number of fecal coliforms (Escherichia coll) in wait time evaluation between unloading and termic treatment of mussels trended in Niterói city - Rio de Janeiro state - Brazil}

\author{
Paulo Carlos Rocha Ferreira Santos, ${ }^{*}$ Luiz Antônio Trindade de Oliveira, ${ }^{\star \star}$ Eliana de Fátima Marques de Mesquita, ${ }^{\star \star}$ \\ Robson Maia Franco, ${ }^{\star \star}$ José Carlos Albuquerque do Prado Carvalho***
}

\begin{abstract}
Resumo
As principais enfermidades transmitidas ao homem por microrganismos, através da ingestão de moluscos bivalves não submetidos ao cozimento ou insuficientemente cozidos, podem ocorrer pela contaminação direta do produto através da água ou indiretamente, durante manipulação, armazenamento, transporte e/ou preparação para o consumo. Com base nesta informação, as amostras de mexilhões foram analisadas quanto aos seus teores de coliformes fecais e presença de Escherichia coli como indicadores da influência do tempo de espera, à temperatura ambiente, entre o descarregamento no cais e o tratamento térmico (beneficiamento realizado na Unidade de Processamento de Mariscos na Associação Livre de Maricultores de Jurujuba - ALMARJ, para posterior comercialização no município de Niterói - estado do Rio de Janeiro - Brasil. A metodologia empregada na enumeração, que está de acordo com HITCHINS et al. (1992) e com os padrões higiênico-sanitários estabelecidos pela Portaria no451(BRASIL, 1997), em vigor na época da realização do trabalho e revogada em janeiro de 2001 pela Resolução RDC no 12 (BRASIL, 2001) permitiu estabelecer um confronto quantitativo, avaliando-se a influência do tempo de espera na quantidade de coliformes fecais presentes nas amostras analisadas. Os resultados do Número Mais Provável de coliformes fecais por grama da amostra (NMP de CF/g) nos mexilhões recém-descarregados variaram de $<0,48$ log 10 a $>3,04$ $\log 10$, e os valores relativos às amostras, após o tempo de espera de quatro horas à temperatura ambiente, variaram entre $0,60 \log 10$ e $3,04 \log 10$. Os resultados obtidos, após estudo estatístico, permitiram concluir que não houve influência significativa na variação de coliformes fecais quanto ao tempo de espera, sendo que em $56,67 \%$ das amostras houve aumento no NMP de CF/g, em 40\% houve diminuição e em 3,33\% não houve alteração, não afastando, assim, a importância dos achados quanto ao risco de ocorrência de enfermidades transmitidas por esses microrganismos no consumo do produto analisado.
\end{abstract}

Palavras-chave: coliformes fecais, Escherichia coli e mexilhões.

\begin{abstract}
The mainly diseases related with microorganisms caused to men through consume of mussels hot heated or poor heated can occur because of direct contamination of the product through water or indirectly during the handling, storage, transport and/or domestic preparation for the consume. Considering this information, in the samples of mussels, fecal coliforms, with Escherichia coli isolament, was quantified as a indicator of wait time influence in room temperature between capture and termic treatment (improvement done at mussels processment unit of Jurujuba Free Mussels Breeders Association ALMARJ - post trending at Niterói city - Rio de Janeiro State - Brazil). The enumeration methodology used, that is in according to HITCHINS et al (1992) and to the hygienic sanitary standards established by 451 government edict (BRASIL, 1997) that was in force at the time of work realization and revocaded in January of the 2001 by the RDC 12 government edict (BRASIL, 2001) permitted to establish a quantitative confront objectiving evaluate the wait time influence under fecal coliform contamination in analyzed samples. The MPN of fecal coliforms per gram of sample (FC/g) in the mussels recently captured varied from $<0,48$ log $10 \mathrm{FC} / \mathrm{g}$ until $>3,04 \mathrm{log} 10 \mathrm{FC} /$ g. In the mussels samples after four hours of wait time at room temperature varied from $<0,60 \mathrm{log} 10 \mathrm{FC} / \mathrm{g}$ until $3,04 \mathrm{log} 10 \mathrm{FC} / \mathrm{g}$. The results, after a statistic analyze; permitted to conclude that there was not significative influence in fecal coliform number because of wait time, however $56,67 \%$ of samples showed increase in FC MPN, $40 \%$ showed decrease and $3,33 \%$ showed not change. This doesn't decrease the results importance as indicator of disease risk occurrence by consume of this product.
\end{abstract}

Keywords: fecal coliforms, Escherichia coli, mussels.

\footnotetext{
* Graduando do Curso de Medicina Veterinária - UFF e Bolsista do CNPq.

** Professor - Departamento de Tecnologia dos Alimentos - Faculdade de Veterinária - UFF.

*** Veterinário - Departamento de Tecnologia dos Alimentos - Faculdade de Veterinária - UFF.
} 


\section{Introdução}

Peixes, mariscos e crustáceos são fontes de alimento possuidores de componentes altamente desejáveis para uma dieta saudável. Entretanto, por fatores diversos, podem se tornar potencialmente de risco para a saúde do consumidor. Em países do "primeiro mundo", como nos Estados Unidos da América (EUA), onde há monitoramento constante do produto oferecido ao mercado, bem como das condições dos locais de procedência, o maior risco de doença aguda está associado ao consumo in natura, particularmente de moluscos bivalves. A contaminação dos mexilhões por bactérias é um problema importante, principalmente em criações e áreas de extrativismo situadas próximo a aglomerados urbanos. Os mexilhões, como demais bivalves, possuem a característica de reter e concentrar organismos patogênicos, agentes de doenças graves como tifo, cólera, tuberculose e hepatite, motivo pelo qual devem ser submetidos a um tratamento de depuração, antes de serem comercializados (Marques e Pereira, 1988).

Conforme a FAO (1974), é importante determinar se os patógenos humanos que vêm sendo introduzidos no meio aquático podem se multiplicar entre peixes e mariscos e, igualmente, estimar a sua importância epidemiológica. Pesquisas já realizadas têm demonstrado que espécies de Salmonella, Pasteurella, Leptospira, Víbrio, Mycobacterium e Nocardia podem se abrigar e se multiplicar nesses organismos, aumentando as fontes de infecção e reinfecção humana. Certas espécies de coliformes fecais estão incriminadas à elevada mortalidade ( $>50 \%$ ) verificada entre pessoas imunocomprometidas ou que sofrem de doenças hepáticas.

Segundo Hitchins et al. (1992), o grupo dos coliformes pertence à família Enterobacteriaceae e caracterizam-se como sendo bastonetes Gram-negativos, aeróbios ou anaeróbios facultativos, fermentadores de lactose com produção de ácidos e gases. Dentro deste grupo, classificam-se os coliformes fecais, cujo principal representante é a Escherichia coli. Caracterizam-se por serem indicadores de contaminação fecal nos alimentos e água, capazes de fermentar a lactose com produção de ácido e gás, quando incubados à temperatura de $44,5^{\circ} \mathrm{C} \pm 0,2^{\circ} \mathrm{C}$, por um período de 24 horas.

Carvalho et al. (1985) esclarecem que os coliformes fecais podem ser considerados como indicadores da presença de bactérias patogênicas e ainda são considerados potencialmente patogênicos.

A Escherichia coli geralmente é considerada um comensal inofensivo, mesofílico típico $\left(37^{\circ} \mathrm{C}\right)$ que cresce na faixa de temperatura de $7^{\circ} \mathrm{C}$ a $50^{\circ} \mathrm{C}$, sendo que algumas cepas enterotoxigênicas crescem a $4^{\circ} \mathrm{C}$. As cepas patogênicas são classificadas de acordo com as suas propriedades de virulência, podendo ser enteropatogênicas (EPEC), enteroinvasivas (EIEC), enteroagregativas (EaggEC), uropatogênicas (UPEC), causadoras de meningite (MENEC) e facultativamente enteropatogênica (FEEC) (JAY, 1994). Seu valor D a $60^{\circ} \mathrm{C}$ é de 0,1 minuto, pode resistir ao congelamento e resfriamento, é capaz de crescer em pH inferior a 4,4, com água de atividade mínima de 0,95 (Adams e Moss, 1997; Figueiredo, 1999). Segundo Eley (1992), para que haja infecção por Escherichia coli é necessário que a dose infectante seja de $10^{5}$ a $10^{7}$ microrganismos por grama de alimento.

Objetivamos avaliar as características higiênico-sanitárias, através da determinação do NMP de CF/g e o isolamento de Escherichia coli, de mexilhões capturados em locais de extrativismo no município de Niterói - RJ, e descarregados no cais da Unidade de Processamento de Mariscos da Associação Livre de Maricultores de Jurujuba (ALMARJ), no momento do descarregamento e após quatro horas de espera em temperatura ambiente, observando, assim, a variação NMP de CF/g durante o tempo de espera de quatro horas entre a captura e o tratamento térmico anterior ao processo de comercialização.

\section{Materiais e métodos}

No período de abril a setembro de 2000 , foram colhidas trinta amostras de mexilhões (cada unidade amostral sendo representada por dez mexilhões) na unidade de processamento de mariscos na Associação Livre de Maricultores de Jurujuba (ALMARJ) - Niterói - Rio de Janeiro, no momento do descarregamento das embarcações.

Os mexilhões vivos, em cada unidade amostral, submersos na própria água do mar, foram transportados em sacos plásticos sob temperatura constante, em embalagem isotérmica, até o laboratório de Controle Microbiológico de Produtos de Origem Animal do Departamento de Tecnologia dos Alimentos da Faculdade de Veterinária da Universidade Federal Fluminense, Niterói - RJ.

Ao chegar no Laboratório, cada unidade amostral foi dividida em duas subunidades amostrais (Tempo 0 e Tempo 4). Os mexilhões componentes das subunidades Tempo 0, imediatamente após a divisão, foram escovados/lavados. A partir deste ponto, todos os procedimentos foram realizados assepticamente, utilizando-se utensílios, vidrarias, soluções e meios de cultura esterilizados. Os mexilhões lavados/escovados foram abertos e tiveram os seus conteúdos cárneos retirados sendo pesados até perfazerem um total de $25 \mathrm{~g}$. Estas subamostras $(25 \mathrm{~g})$ foram colocadas em embalagens plásticas de "Stomacher" que, em seguida, foram preenchidas com 225mL de Solução Salina Peptonada a 0,1\%(SSP $0,1 \%$ ), e então levadas ao aparelho "Stomacher" para homogeneização à velocidade máxima por 30 segundos. Após este processamento, da solução obtida, diluição $1 / 10$, obtiveram-se as diluições $1 / 100$ e $1 / 1000$, utilizando-se tubos de SSP $0,1 \%$ com $9 \mathrm{~mL}$.

A partir das diluições obtidas, analisaram-se as amostras de mexilhões quanto ao Número Mais Provável de Coliformes Fecais por grama da amostra (NMP de CF/g) e quanto à presença de Escherichia coli, conforme metodologia descrita por Hitchins et al. (1992).

Os mesmos procedimentos foram realizados nas 30 subunidades amostrais Tempo 4, após terem permanecido por um tempo de quatro horas à temperatura ambiente, simulando, assim, o tempo de espera entre o desembarque e tratamento térmico prévio à comercialização dos mexilhões, feito na unidade de processamento de mariscos da Associação Livre de Maricultores de Jurujuba (ALMARJ) - Niterói - Rio de Janeiro. 


\section{Resultados}

Isolou-se Escherichia coli em $100 \%$ das amostras analisadas. Em 56,67\% das amostras houve aumento no NMP de $\mathrm{CF} / \mathrm{g}$, em $40 \%$ houve diminuição, e em 3,33\% não houve alteração (Gráfico 1). Os valores de NMP de CF/g das subunidades Tempo 0 variaram de $<0,48 \log 10$ a 3,04 $\log 10$, com um NMP médio de 2,33 log $10 / \mathrm{g}$ e das subunidades Tempo 4 variaram de $0,60 \log 10$ a $3,04 \log 10$ com um NMP médio de 2,41 $\log 10 / \mathrm{g}$.

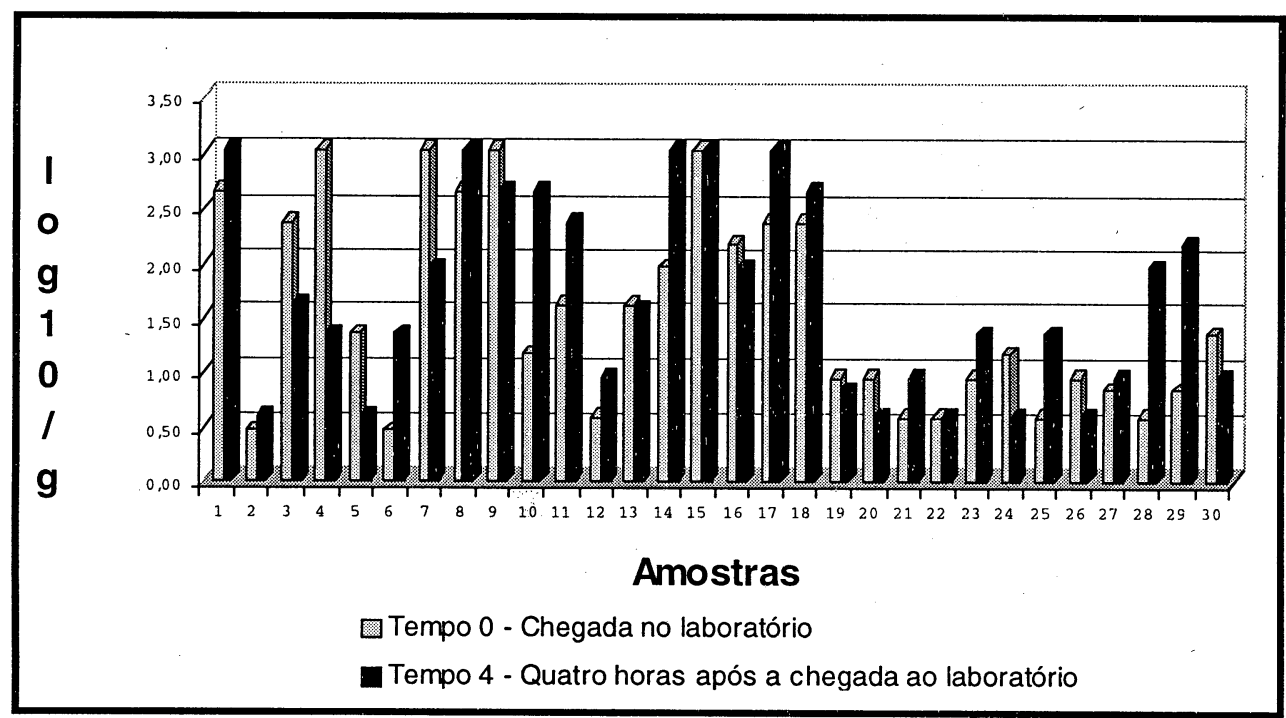

Gráfico 1: Comparação entre os valores do NMP de coliformes fecais entre as amostras de mexilhão no Tempo 0 e no Tempo 4

Em algumas amostras foram isoladas cepas de Escherichia coli atípica, Escherichia blattae, Escherichia fergusoni e Klebsiella pneumoniae.

A análise estatística dos resultados obtidos no experimento demonstrou que a diferença entre os valores de NMP de CF/ $\mathrm{g}$ das subunidades amostrais no Tempo 0 e no Tempo 4 não foi significativa $(p>0,05)$.

\section{Discussão}

Organismos filtradores, tais como os mexilhões, possuem a capacidade de concentrar microorganismos e substâncias químicas, o que faz deles indicadores de poluição(Lizärraga-

\section{Referências}

ADAMS, M.R.; MOSS, M.O. Microbiología de los alimentos. 1.ed. Zaragoza (Espanha): Editorial Acribia, 1997. 463 p.

BRASIL. Secretaria de Vigilância Sanitária. Portaria ne 451, de 19 de setembro de 1997. Princípios Gerais para o Estabelecimento de Critérios e Padrões Microbiológicos para Alimentos. Diário Oficial da União. Brasília, DF, p. 21005-21012, 22 set. 1997.

BRASIL. Ministério da Saúde. Resolução - RDC n 12, de 2 de janeiro de 2001. Regulamento Técnico sobre Padrões Microbiológicos para Alimentos. Diário Oficial da União. Brasília, DF, n. 7-E, Seção 1, p. 4553,10 jan. 2001.
Partida e Cädenas, 1996). Esses poluentes se distribuem e são seqüestrados em qualquer tecido do corpo desses animais, (Power e Collins, 1990).

Segundo Bussani (1983), as enfermidades causadas ao homem através do consumo de mexilhões podem ser de origens bacteriana, viral, micótica, parasitária, alérgica ou indeterminada, e quanto aos microrganismos contaminantes dos mexiIhões, a Escherichia coli é a mais conhecida, sendo também utilizada na avaliação da qualidade das águas, cuja presença indica maior ou menor contaminação de origem fecal. O mesmo autor esclarece que a Escherichia coli, em relação a outros microrganismos, possui maior resistência aos agentes externos, ao calor, ao ácido fênico; no mar, ela apresenta diversos comportamentos e pode sobreviver geralmente por até trinta dias.

Apesar do exposto, a Legislação Brasileira não estabelece limites quanto à quantidade de CF presentes no conteúdo cárneo de mexilhões "em natureza". Sendo assim, confrontamos os valores encontrados com os valores estabelecidos pela Food and Drug Administration (FDA, 1992), que adota como limite 300 coliformes fecais por $100 \mathrm{~g}$ de amostra, e assim observou-se que apenas $3,33 \%$ seriam consideradas aceitáveis. Se levada em consideração a legislação italiana (Bussani, 1983), que estabelece o limite de 39 Escherichia coli por $100 \mathrm{~g}$ de amostra, $100 \%$ das amostras analisadas seriam consideradas inaceitáveis.

\section{Conclusões}

Embora a variação do teor de CF entre o Tempo 0 e o Tempo 4 não tenha sido estatisticamente significativa $(p>0,05)$, talvez devido à condição climática de outono e inverno, onde as temperaturas são mais amenas, a presença da Escherichia coli em $100 \%$ das amostras prevalece como indicador de contaminação fecal, constituindo, assim, um risco em potencial para os consumidores do produto analisado, com a possibilidade de ocorrência de Enfermidade Transmitida por Alimento (ETA).

BUSSANI, M. Guia Práctica del cultivo de mejillón. Zaragoza (Espanha): Editorial Acribia, 1983, p. 161-178.

CARVALHO, J.C.A.P.; OLIVEIRA, L.A.; FRANCO, R.M.; BASTOS, L.M. Incidência de coliformes totais e fecais em embutido frescal (lingüiça) comercializado na cidade de Niterói. CONGRESSO BRASILEIRO DE CIÊNCIA E TECNOLOGIA DE ALIMENTOS, Fortaleza, 1984. Anais... p. 236-237.

CARVALHO, J.C.A.P.; OLIVEIRA, L.A.T;; FRANCO, R.M. Incidência de coliformes totais e fecais em embutido frescal (lingüiça) comercializado na Cidade de Niterói. Revista Higiene alimentar. v. 4, n. 2, p. 136-137, 1985. 
ELEY, A. R. Intoxicaciones alimentarias de etiología microbiana. Zaragoza (Espanha): Editorial Acribia, 1992. 57p.

FAO. Hygiène du Poisson et des Fuits de Mer. Rapport d'un Comité d'experts de l'Oms Réuni en Coopération avec la FAO. Organizations des Nations Unies pour l'Alimentation et l'Agriculture. Rome: Publié par la FAO et l'Oms, 1974, $66 \mathrm{p}$.

FIGUEIREDO, R. M. Manual de procedimentos e desenvolvimento. São Paulo: R.M. Figueiredo, 1999, 161 p.

FOOD and DRUG ADMINISTRATION - FDA. Sanitation of Shellfish Growing Areas. National Shellfish Sanitation Program. Manual of Operations-part 1. Washington, D.C: US Department of Health and Human Services, Public Health Service, 1992,150 p.

HITCHINS, A.D.; HARTMAN, P. A.; TODD, E. C.D. Coliforms- Escherichia coli and its toxins. In: VANDERZANT, C., SPLITTSTOESSER, D. F.
Compendium of Methods for the Microbiological Examination of Foods. Washington,DC: APHA, 1992. 1219 p. Cap. 24, p. 325-369.

LIZÁRRAGA-PARTIDA, M. L.; CÁDENAS, G. V. Influence of water circulation on marine and fecal bactéria in a mussel growing area. Marine Pollution, v. 32, n. 2, 1996, p. 196-201.

MARQUES, H. L. A.; PEREIRA, R.T.L. Mexilhões-Biologia e Criação. Boletim Técnico no 12, Instituto de Pesca-Secretaria de Agricultura e Abastecimento - Coordenadoria de Pesquisa agropecuária - Governo do Estado de São Paulo, 1988, 32 p.

POWER, U. F.; COLLINS, J. K. Tissue Distribution of a coliphage and Escherichia coli in Mussels after Contamination and Depuration. Applied and Environmental Microbiology. v. 56, n. 3, 1990, p. 803807. 